\title{
Research on the Mobile News Client in the Big Data Era
}

\author{
Qiaochu Xu \\ School of Journalism and Communication, Shandong University, No.27, Shanda South Road, Jinan, \\ Shandong Province, China \\ lbt1230@126.com
}

Keywords: big data, journalistic professionalism, mobile news client

\begin{abstract}
In recent years, the importance of big data has been rising. As a new tool and technology, great changes have taken place in the development of mobile news client. At the same time, it has also impacted the traditional mode of news communication. When everything was regarded as data, media employee began to pursue the correlation rather than the causality, accept the hybridity rather than the accuracy. With the benefit caused by big data, the technicism and commercialism represented by big data also brings the problems such as the narrowing of information, machines replaced editors, privacy violations and so on, impacting the journalistic professionalism continuously.
\end{abstract}

\section{Mobile News Client}

There's no specific definition of the mobile news client, under the basic cognition of client, it can be interpreted as an application that communicating text, pictures, video and other media information content through mobile terminal such as tablet PC or smartphone, corresponding to the servers.

There are many ways to classify mobile news clients, which can be divided into the following three types according to their content production types:

(1) Portal type of mobile media client that center on making content independently:

This kind of mobile news client produce content by the professional media organizations, the content is systematic, and the client has advantages in mining depth, but also has weaknesses such as the singular risk of views and the damage of comprehensiveness and objectivity.

(2) Integrated type of mobile media client that center on search referral:

This kind of mobile news client produce content by big data algorithms, integrating and recommending news by digging the user's habits, social relations and other data. The disadvantage is the information is too complex, and the source is miscellaneous, the quality is uneven.

(3) Conjunctive type of mobile media client:

This kind of mobile news client not only have the news made independently, but also allow users to subscribe to topics and recommend news for their own interest.

Since the big data appeared, mobile news client can be more accurate to cater to the needs of the audience: recommending news by algorithm only, no professional media organizations, even no media practitioners to participate in.

\section{Big Data in Content Production of Mobile News Client}

The use of big data has three prerequisites: the maturity of machine learning algorithms, the popularity of open source platforms, and the rapid development of mobile internet. Under this premise, based on the three tools -- generalization and summarization, A/B test, double-blind experiment and a series of algorithms which use ranking model and recalling model as recommended algorithms, constructed a fast and accurate recommendation platform. 
The advantages of the mobile news client in the big data era are as follows:

(1) News recommendation:

The updating algorithm can recommend news for users quickly and accurately, and when the user use new products on the first time, there is no sufficient historical data to support the recommendations. Through the related and other social platforms such as micro-blog alliance, the initial interest distribution can match the social data, personalized recommendation can be formed, basing on the interest map of micro-blog, that is the "cold start" of recommendation engine.

(2) Social function:

Clients can import the users of other applications and obtain their dynamic information. Another bright spot is the comments and sharing, there also introduce the recommendation system in the comments, aggregating comments in various social platforms on the same article, recommending the comments according to the characteristics of the users at the same time, so that the users can read the reviews they are most interested in.

(3) Ductility:

In addition to the basic news recommendation, the clients begin to try to concentrate on the production of high-quality content while aggregating contents from various platforms, in order to make up their deficiencies in copyright issues.

\section{The Impact of Big Data to Mobile News Client: Deconstruction and Reconstruction of Journalistic Professionalism}

\subsection{The deconstruction of journalistic professionalism:}

(1) The changes of four elements:

For news agencies, journalists in news, news value and news ethics of journalistic professionalism, the mobile news client on the big data era means that professional news organizations began to be replaced by the technical department, the status of professional journalists is being influenced, they are encountering identity crisis. The content production of mobile news client completely rely on data search and extraction, there's no news content of the traditional way in the production process, which leads to the result that traditional news production mode is broken, the content and value orientation can not be effective monitored, it is difficult to meet the timeliness, significance and importance of the elements. The integrated search platform itself has no ability to identify, now the news literacy of audience still need to be improved, the extreme trend, undisguised trend, and deflective trend of reports are still popular in people. The permanence, replicability and indefinite divisibility of data decide that the invasion of privacy will inevitably become a thorny problem in the development of big data and damage the journalistic ethics.

(2) Information cocoons:

"Information cocoons" was raised for the first time by professor Cass Sunstein, in the book $<$ Republic.com>, He believes that the Internet makes it easier for people to get what they like and refuse to accept the information they don't like. In fact, what people get is "narrowing" information. As a mobile news client, the size of mobile phone screen and the psychology of audience's quick reading can be one of the cause of narrowing information. Personalized customization has also accelerated the construction of "information cocoons". Media should not only satisfy the audience's taste of news, but also should have the function of monitoring environment, meet the need of people's social environment perception. The repeated acquisition of the same type of news, to a certain extent, reduces the significance of information acquisition activities.

(3) Writing Robert:

The machine makes the journalists no longer need to deal with fixed format of news reports, which means that in the future, the number of journalists will be significantly reduced, while the core ability and skill requirements of journalism will also be changed. At the same time, the traditional boundaries of news are not clear, and the proportion of information services content is increasing. In the premise of accepting the reality, the media should actively explore the 
complementary function between man and machine, and build a new ecological order in the field of communication jointly.

\subsection{The reconstruction of journalistic professionalism:}

Big data does not mean the overall decline of journalistic professionalism, from a dialectical point of view, there are some new characteristics and connotations of journalistic professionalism in the new communicative context made by big data era.

(1) Journalistic professionalism does not disappear completely:

First, the development of technology strengthens the quality requirements of media, professional barriers still exist, even increase to a certain extent. In big data era, the journalists can not just interview or write, but to master certain technical knowledge, especially data knowledge, they should transform to all-round talents.

Second, as a tool, big data still lack of artificial intelligence, the position of journalists is still vital, journalistic professionalism is still a useful concept. For in-depth research, technology can provide data, but the hidden logical relationship, especially the secret relationship between irrelevant data, still need professionals to find.

Third, there form a more challenging journalistic professionalism under the background of big data. The new technology provides more platform for the development of journalism, the ideal of journalistic professionalism has not disappeared, but developing more complicatedly.

(2) The transformation of communication subject:

The transformation of communication subject is the primary reflection of reconstruction in the new communicative context, the era of big data has new requirements for the professional news organizations and journalists.

The traditional news organizations are not only content providers, but also controllers of communicative channels. News organizations under the new technology should realize that the key to future development is not to expand the channels of communication, but to produce content with high professional level and to supply or sell it to other information platforms. No matter how the technology develops, "content first" is always the news concept that is not out of date. Good news content can play a leading role in the public with its credibility and authority.

For the professional journalists, they should have the awareness that no matter how technology changes, journalists should always become an influential and credible "opinion leaders", to provide professional information for the public, and reshape their position. The journalists of new era should have higher data literacy and data feeling, learning to participate in the news activities of new environment by mastering new technology, participate in the information filtering and interpretation, find valuable news topic, and provide suggestions for the audience, guide the public opinion to the right direction.

(3) The reconstruction of news value and news ethics standards:

One of the most important reason that why journalistic professionalism can be more specialized in new era is that big data provides a new guarantee for the truthfulness and objectivity of news: First, from partial presentation to comprehensive objectivity, the news of big data era focuses on all the data of related events, and ensures the truth and comprehensiveness of news data to the greatest extent by collecting, filtering and mining data. Second, from the surface to the deep, journalistic professionalism requires the essential truth, in a continuous series of reports, big data technology can find a logical potential link and provide new ideas for the news by doing cross-contrast of a large number of data, or find the anomaly of and capture the little known details by analyzing all the data. In addition, the unique prediction of big data technology also developed the traditional news value in "timeliness" and "usefulness", let the public know the trend of events which has not yet happened, broke through cognition on the "timeliness" in the traditional news value, and the prediction results can help the audience's life by health, consumption and the other directive report. Big data also adds new content and standards to the judgment of news value - "interactivity". Our society is always in the flow of change, big data can not only give a result, but also show the change process of the news. news is no longer changeless, but to be reported as a continuous and 
developing process.

\section{Conclusion}

The application of big data in mobile news client let us realize: the use of big data not only provides new standards of news value, but also changes and perfects the requirements of news ethics to a certain extent. First, big data emphasizes individuality and human orientation, which makes it necessary for news ethics to advocate humanistic care. In the era of big data, media should give more consideration to the feelings of the audience, regard the care for public as a standard of behavior; Second, it should pay more attention to ethics for the application of data management, it requires we to face the incomplete data directly, and actively build data services and interactive platform, pay attention to the interaction mechanism, and lead a healthy ecological ecology of data; Pay attention to identify the authenticity of data, improve data monitoring mechanism, unify statistical standards, avoid the abuse and misuse, play a gatekeeper role in journalism actively, improve self-discipline consciousness; enhance the comprehensive ability to use data, establish a big data market in an orderly and sustainable development, cultivate the sense of responsibility and humane care of data application, and realize the standardization of the application and development of big data.

\section{References}

[1] ViktorMayer-Schönberger. Kenneth Cukier. Big Data: A Revolution that will Transform How We Live, Work, and Think[M]. Zhejiang: Zhejiang People’s Publishing House. 2013.

[2] Pinjue Che. Decisive Big Data: A Tool to Control the Future's Business[M]. Zhejiang: Zhejiang People’s Publishing House. 2014.

[3] Fei Wu. Study of Journalism[M]. Beijing: China Renmin University Press. 2009. 